\title{
Paenibacillus turicensis sp. nov., a novel bacterium harbouring heterogeneities between 165 rRNA genes
}

Department of Medical Microbiology, University of Zürich, Gloriastrasse 30/32 8028 Zürich, Switzerland

\author{
Philipp P. Bosshard, Reinhard Zbinden and Martin Altwegg
}

\begin{abstract}
Author for correspondence: Philipp P. Bosshard. Tel: +41 1634 2700. Fax: +41 16344906 e-mail: philboss@immv.unizh.ch
\end{abstract}

\begin{abstract}
A Gram-positive, facultatively anaerobic, rod-shaped, endospore-forming bacterium (strain MOL722') was characterized using phenotypic and molecular methods. Fatty acid analysis and biochemical examination indicated that the isolate belongs to the Gram-positive bacteria with low DNA G+C content, probably to the genus Paenibacillus. Direct sequencing of the 16S rRNA gene showed ambiguities, suggesting heterogeneity. Cloned 16S rDNA yielded seven different sequences varying at 15 positions, with one being an insertion. The isolate shares $\mathbf{9 8 . 5} \%$ sequence similarity with Paenibacillus sp. P15-9, but less than $94 \%$ similarity with other paenibacilli and bacilli. Phylogenetic analysis with different treeing methods revealed that strain $\mathrm{MOL722}^{\top}$, together with Paenibacillus sp. P15-9, forms a novel monophyletic clade within the genus Paenibacillus. Based on phenotypic and phylogenetic evidence, it is proposed that the unknown bacterium is classified as the novel species Paenibacillus turicensis sp. nov., the type strain of which is strain MOL722' $\left(=\right.$ DSM $14349^{\top}=$ NCCB 100011').
\end{abstract}

Keywords: Paenibacillus turicensis, 16S rDNA, 16S rRNA heterogeneities

\section{INTRODUCTION}

Based on phylogenetic data from 16S rDNA sequences, Ash et al. (1993), separated the so-called group 3 bacilli as the new genus Paenibacillus. Since then, the genus has grown from 11 to over 30 species. Paenibacilli have been isolated from a variety of sources including soil, water, the plant rhizosphere, food and diseased insect larvae, but not from clinical specimens (Daane et al., 2002). Strain MOL $722^{\mathrm{T}}$ was isolated from the valve of a cerebrospinal fluid shunt of a 48-year-old man. The Gram-positive rod could not be identified by using routinely performed diagnostic methods, whereas sequencing of the $5^{\prime}$ end of the $16 \mathrm{~S}$ rDNA indicated moderate similarities $(<92 \%)$ to members of the genus Paenibacillus. We decided to investigate this strain by biochemical and molecular means.

Characterization of $16 \mathrm{~S}$ rRNA gene sequences has become a common method for identification and

Published online ahead of print on 14 June 2002 as DOI 10.1099/ ijs.0.02105-0.

The GenBank accession numbers for the $16 \mathrm{~S}$ rDNA sequences of strain MOL722 ${ }^{\top}$ are AF378694-AF378700. classification of bacteria. The molecular approach has also been used extensively for bacterial phylogeny (Woese et al., 1990) and analysis of bacterial diversity (Bosshard et al., 2000; Fox et al., 1980). Many studies proposing novel species or higher-level groups include 16S rDNA sequencing (Ash et al., 1993; Daane et al., 2002; Chung et al., 2000; Stackebrandt et al., 1997). Although not intensively studied, intraspecies and even intrastrain 16S rRNA gene heterogeneities are a common phenomenon. Clayton et al. (1995) reported unexpected high levels of intraspecific variation (within and between strains) of prokaryotic 16S rRNA sequences deposited in GenBank. The variations were more widespread than predicted from sequencing errors. Several publications deal with intraspecific polymorphisms in 16S rRNA genes (Bricker, 2000; Cilia et al., 1996; Liefting et al., 1996; MartínezMurcia et al., 1999; Ninet et al., 1996; Nubel et al., 1996; Pettersson et al., 1998; Reischl et al., 1998). Remarkable effects on phylogeny and biodiversity estimates have been reported (Cilia et al., 1996; Clayton et al., 1995).

Full-length sequencing of PCR-amplified 16S rDNA from strain MOL $722^{\mathrm{T}}$ resulted in a mixture of sequences starting at position 1138 (Escherichia coli 
numbering; Brosius et al., 1978). Therefore, multiple clones of $16 \mathrm{~S}$ rDNA were sequenced and revealed an insertion of one nucleotide at position 1138 in one type of $16 \mathrm{~S} \mathrm{rDNA}$ within this strain. In total, seven different 16S rRNA genes were determined, with 15 variable nucleotide positions.

\section{METHODS}

Bacterial strain and culture. Strain MOL $722^{\mathrm{T}}$ was isolated from the valve of a cerebrospinal fluid shunt of a 48-year-old man with hydrocephalus that he developed after an accident. A second control sample was sterile. The isolate was cultivated on different standard media under oxic and anoxic conditions (see phenotypic characteristics in Results and Discussion). Trypticase soy broth was used for determining the $\mathrm{pH}$ optimum for growth, the sodium chloride tolerance, lysozyme tolerance and doubling time. The strain was maintained in skim milk at $-70^{\circ} \mathrm{C}$.

Phenotypic characteristics. The morphological properties were examined by light and transmission electron microscopy. Biochemical reactions were determined by using the API 20E and API 50CHB systems according to the manufacturer's instructions (API bioMérieux) and by an in-house identification scheme for rapidly and aerobically growing Gram-positive rods (von Graevenitz \& Funke, 1996). Cellular fatty acids were analysed with the MIDI system (Microbial Identification) as described previously (von Graevenitz et al., 1994). Metabolic acids were identified by GLC on a GC 8000 (CE Instruments).

\section{Genotypic analysis}

DNA extraction and PCR. DNA was extracted from a single colony using the PrepMan reagent according to the manufacturer's protocol (Applied Biosystems). For blotting, high- molecular-mass chromosomal DNA was extracted using standard methods. The $16 \mathrm{~S}$ rRNA gene was amplified using primers 1 and 12 (Table 1). The temperature and duration for denaturation, annealing and extension were $90^{\circ} \mathrm{C}$ for $15 \mathrm{~s}, 50^{\circ} \mathrm{C}$ for $30 \mathrm{~s}$ and $70^{\circ} \mathrm{C}$ for $45 \mathrm{~s}$. Forty cycles were performed using AmpliTaq DNA polymerase LD (Applied Biosystems).

Cloning. PCR products obtained with primers 1 and 12 were loaded on an agarose gel and bands of the correct size were excised and purified (Gel extraction kit, Qiagen). After standard A-tailing, the PCR products were ligated into the vector pCR2.1 (Stratagene) and the plasmids were used to transform competent cells of $E$. coli TOP $10 \mathrm{~F}^{\prime}$ according to the manufacturer's instructions. Plasmid DNA was prepared from white colonies as described previously (Berghammer \& Auer, 1993). Plasmids containing inserts of the correct size were sequenced with 12 different primers (Table 1) using the BigDye kit and an automatic DNA sequencer (model 310; Applied Biosystems). The primers, except numbers 6 and 7 , were derived from Lane (1991). Most of them were modified to have approximately the same melting temperature and are specific for the domain Bacteria. Primer 6 was described previously (Fischer-Romero et al., 2000); primer 7 is the reverse-complement of primer 6

Blotting. High-molecular-mass DNA was digested with $H$ indIII and KpnI, loaded on a $0.8 \%$ agarose gel and blotted using standard methods. Digoxigenin-labelled probes for hybridization were DIG-Bact-8s, DIG-MOL722-GTAA and DIG-MOL722-TTC (Table 1). Hybridization was performed at $48^{\circ} \mathrm{C}$ for $4 \mathrm{~h}$. Detection was done colorimetrically using NBT and BCIP.

Phylogenetic analysis. The $16 \mathrm{~S}$ rDNA sequences of strain MOL 722 ${ }^{\mathrm{T}}$ (homologous to E. coli positions 8-1542; Brosius et al., 1978) were aligned with representative sequences (accessions and collection numbers of the respective strains

Table 1. Primers for amplification and sequencing of total $16 \mathrm{~S}$ rDNA and probes for Southern blot hybridization

Primers 1 and 12 were used for amplification; primers 1-12 were utilized for sequencing.

Positions are given relative to the E. coli numbering (Brosius et al., 1978).

\begin{tabular}{|llc|}
\hline Primer & \multicolumn{1}{c|}{ Sequence $\left(\mathbf{5}^{\prime} \rightarrow \mathbf{3}^{\prime}\right)$} & Position \\
\hline 1. Bact-8s-20 & AGAGTTTGATCMTGGCTCAG & $8-27$ \\
2. Bact-339a-17 & GCTGCCTCCCGTAGGAG & $355-339$ \\
3. Bact-341s-17 & CCTACGGGAGGCAGCAG & $341-357$ \\
4. Bact-536a-18 & GTATTACCGCGGCTGCTG & $536-519$ \\
5. Bact-519s-18 & CAGCAGCCGCGGTAATAC & $519-536$ \\
6. Bact-787a-20 & GGACTACHAGGGTATCTAAT & $806-787$ \\
7. Bact-787s-20 & ATTAGATACCCTDGTAGTCC & $787-806$ \\
8. Bact-907s-20 & AAACTCAAAKGAATTGACGG & $907-9267$ \\
9. Bact-1098a-17 & GGGTTGCGCTCGTTGCG & $1114-1098$ \\
10. Bact-1098s-17 & CGCAACGAGCGCAACCC & $1098-1114$ \\
11. Bact-1389s-18 & CTTGTACACACCGCCCGT & $1389-1406$ \\
12. Bact-1525a-17 & AAGGAGGTGATCCARCC & $1541-1525$ \\
DIG-Bact-8s & AGAGTTTGATCMTGGCTCAG* & $8-27$ \\
DIG-MOL722-TTC & AGCAATTCGGTTGGGCACT* & $1130-1148$ \\
DIG-MOL722-GTAA & AGCAAGTAAGGTTGGGCAC* & $1130-1147$ \\
\hline
\end{tabular}

* Probes are digoxigenin-labelled at the $5^{\prime}$ end. 
are shown in Fig. 4) of all validly published paenibacilli and other taxa obtained from the GenBank database using PILEUP from the Wisconsin GCG package (Devereux et al., 1984). Phylogenetic trees with bootstrap analysis were constructed with the neighbour-joining, UPGMA, FitchMargoliash and maximum-parsimony methods using the programs SEQBOOT, DNADIST, NEIGHBOR, FITCH, KITSCH, DNAPARS and CONSENSE of the PHYLIP program package (Felsenstein, 1989). The trees were rooted using E. coli (accession no. J01859) as an outgroup. In addition, the sequences were fitted into an alignment of about 6500 full or partial primary structures provided with the ARB software package (Strunk et al., 1999) as described elsewhere (Bosshard et al., 2002).

\section{RESULTS AND DISCUSSION}

\section{Phenotypic characteristics}

Phenotypic characteristics of strain MOL 722 ${ }^{\mathrm{T}}$ and other selected paenibacilli are shown in Table 2. Cells of strain MOL $722^{\mathrm{T}}$ were Gram-positive, motile, sporeforming rods, approximately $1.5-3 \times 0 \cdot 5-1 \mu \mathrm{m}$ in size. The isolate produced ellipsoidal endospores in swollen sporangia in the terminal or subterminal region of the cell (Fig. 1). Strain MOL $722^{\mathrm{T}}$ was facultatively anaerobic and grew on sheep-blood, chocolate and Brucella agars. Growth was also observed in thioglycollate, Todd-Hewitt and trypticase soy broth. In Luria-Bertani medium, very weak growth was observed, and no growth occurred on MacConkey agar. On sheep-blood agar, the non-haemolytic colonies were greyish-white with a convex elevation and regular margins. Growth was found to be optimal at $37-42^{\circ} \mathrm{C}$, with a range from 15 to $48^{\circ} \mathrm{C}$. In contrast, the optimum growth temperature for the majority of Paenibacillus species is $28-30{ }^{\circ} \mathrm{C}$ (Shida et al., 1997a). However, only recently, several novel Paenibacillus species have been described with temperature optima around $37-40{ }^{\circ} \mathrm{C}$ (Chung et al., 2000; Shida et al., 1997b; Tcherpakov et al., 1999; Yoon et al., 1998). The doubling time at optimal $\mathrm{pH}$ and temperature was $45 \mathrm{~min}$ as measured by $\mathrm{OD}_{600}$.

In contrast to almost all other Paenibacillus species (Shida et al., 1997a), strain MOL 722 ${ }^{\mathrm{T}}$ was negative for catalase. Oxidase was also negative. The strain was susceptible to vancomycin but resistant to penicillin. Acid production as shown in Table 2 was tested using the API 50CH system. In contrast to other paenibacilli (Daane et al., 2002), trehalose was not fermented. Although the T-values were low, the strain was identified as Bacillus circulans $(\mathrm{T}=0.61, \% \mathrm{id}=94.5)$ or Bacillus coagulans ( $\mathrm{T}=0 \cdot 63, \% \mathrm{id}=3 \cdot 2$ ) by the API $50 \mathrm{CH}$ system. This illustrates the general problem of (mis-)identification by biochemical means for species not included in a given database. The results of cellular fatty acid analysis are shown in Table 3. A predominance of anteiso- $\mathrm{C}_{15: 0}$ is typical for paenibacilli; however, these are the highest reported values of $\mathrm{C}_{16: 0}$, $\mathrm{C}_{14: 0}$ and iso- $\mathrm{C}_{14: 0}$ for members of this genus (Shida et al., 1997a). End products of glucose fermentation were acetate and lactate only.
Thus, strain MOL $722^{\mathrm{T}}$ can be differentiated from other paenibacilli by its negative catalase, its inability to ferment trehalose, its higher temperature optimum for growth and its relatively high contents of $\mathrm{C}_{16: 0}$, $\mathrm{C}_{14: 0}$ and iso- $\mathrm{C}_{14: 0}$ fatty acids.

\section{Genotypic analysis}

To investigate the genealogical classification of the isolate, comparative $16 \mathrm{~S}$ rRNA gene sequence analysis was performed. Direct sequencing failed in both directions from position 1144 onward (position 1138 , E. coli numbering; Brosius et al., 1978). From this nucleotide on, the sequence was ambiguous, as if two different sequences were interleaved. Later, sequencing of cloned 16S rDNA revealed an insertion of one nucleotide in a stretch of three and four variable positions, respectively, on one type of the gene, leading to a sequence shift.

Sequencing of various clones containing 16 rRNA genes revealed the presence of several rRNA operons. Besides the above-mentioned highly variable region at positions 1141-1144 (types A and B), a second highly variable region was found at positions 195-198 (types $1-3)$. In total, 15 variable positions were detected by comparing plasmid insert sequences (Table 4). Ambiguities that occurred in only one clone were interpreted as possible errors of the polymerase during amplification and are therefore not taken into account. In pairwise comparisons, two to 12 transitions and transversions are equivalent to sequence differences of 0.15 to $0.77 \%$ within the total $16 \mathrm{~S}$ rRNA gene. The variable nucleotide positions detected correspond to rapidly evolving nucleotides in the regions $\mathrm{V} 1, \mathrm{~V} 2, \mathrm{~V} 6$, V7, V9 and the stem of helix 50 (according to Neefs et al., 1993). The potential secondary structures of the two highly variable regions (positions 195-198 and 1141-1144) in biologically active rRNAs are shown in Fig. 2. All differences at positions 195-198 in helix 10 (V2) are of the transition type $\mathrm{U}: \mathrm{A} \leftrightarrow \mathrm{U}: \mathrm{G}$ and vice versa (Fig. 2a). In rRNAs, non-canonical pairs $U: G$ are frequently characteristic features (Gutell et al., 1994). The differences at positions 1141-1144 (V7) are located in the terminal loop of helix 43 (Fig. 2b). Thus, the exchanges do not interfere significantly with secondary structure formation.

Southern blot hybridization experiments (Fig. 3) were designed to verify the presence of different $16 \mathrm{~S}$ rDNA sequences in the genome of strain MOL $722^{\mathrm{T}}$. For restriction, two enzymes (HindIII and $K p n I$ ) were used that cut once in the $16 \mathrm{~S}$ rDNA. The probe sequences are shown in Table 1. Probe DIG-Bact-8s generated eight (HindIII) and six (KpnI) hybridization signals (Fig. 3a, lanes 2 and 3). Of the eight bands from the digestion with HindIII, two are double bands, which were interpreted with care, i.e. six to eight different rRNA genes. The probes DIG-MOL722-TTC and DIG-MOL722-GTAA are two newly designed probes directed against the variable regions of clone types $\mathrm{A}$ and $B$ at positions 1141-1144. With these probes, three 
Table 2. Phenotypic characteristics of strain $\mathrm{MOL}_{22}{ }^{\top}$ and other Paenibacillus species

Taxa: 1, MOL722 ${ }^{\mathrm{T}}$ (data from this study); 2, P. alvei; 3, P. pabuli; 4, P. polymyxa; 5, P. validus (data for taxa $2-5$ from Daane et al., 2002; Shida et al., 1997a, b); 6, P. naphthalenovorans (Daane et al., 2002); 7, P. jamilae (Aguilera et al., 2001); 8, P. koreensis (Chung et al., 2000); 9, P. campinasensis (Yoon et al., 1998); 10, P. dendritiformis (Tcherpakov et al., 1999); 11, P. thiaminolyticus (Shida et al., 1997a). All strains were negative for $\mathrm{H}_{2} \mathrm{~S}$ production and tryptophan deaminase (not reported for taxa 7-11) and lysine decarboxylase (not reported for taxa 7, 9-11). None of the strains produced acid from erythritol, L-xylose, dulcitol, Dxylose, D-fucose, D-arabitol, L-arabitol, 2-ketogluconate or 5-ketogluconate (not reported for taxa 8-11). All strains produced acid from maltose and sucrose, but not from D-tagatose (not reported for taxa 9-11). +, Positive; -, negative; v, variable; NR, not reported.

\begin{tabular}{|c|c|c|c|c|c|c|c|c|c|c|c|}
\hline Characteristic & 1 & 2 & 3 & 4 & 5 & 6 & 7 & 8 & 9 & 10 & 11 \\
\hline Gram reaction & $\mathrm{V}$ & NR & + & NR & NR & + & $\mathrm{V}$ & + & $\mathrm{V}$ & - & NR \\
\hline Anaerobic growth & + & + & $\mathrm{V}$ & + & - & - & + & + & + & + & + \\
\hline \multicolumn{12}{|c|}{ Temperature for growth $\left({ }^{\circ} \mathrm{C}\right)$} \\
\hline Optimum & $37-42$ & 28 & $28-30$ & 30 & $28-35$ & $30-37$ & 30 & $38-40$ & 40 & 37 & 28 \\
\hline Range & $15-48$ & NR & NR & NR & NR & NR & $30-40$ & $10-50$ & $10-45$ & $20-45$ & NR \\
\hline \multicolumn{12}{|l|}{$\mathrm{pH}$ for growth } \\
\hline Optimum & 7 & NR & NR & NR & NR & NR & 7 & NR & 10 & NR & NR \\
\hline Range & $5 \cdot 5-9 \cdot 5$ & NR & NR & NR & NR & NR & $5-12$ & NR & $7 \cdot 5-10 \cdot 5$ & NR & NR \\
\hline \multicolumn{12}{|l|}{ Growth at/with: } \\
\hline $10^{\circ} \mathrm{C}$ & - & - & + & - & - & - & - & NR & + & - & NR \\
\hline $50^{\circ} \mathrm{C}$ & - & - & - & - & + & - & NR & NR & - & - & - \\
\hline $\mathrm{pH} 5 \cdot 6$ & + & - & + & + & NR & NR & + & NR & - & + & - \\
\hline $3 \% \mathrm{NaCl}$ & + & - & + & + & - & - & - & NR & + & + & $\mathrm{V}$ \\
\hline $5 \% \mathrm{NaCl}$ & + & - & - & - & - & - & - & NR & + & + & $\mathrm{V}$ \\
\hline 0.001 \% Lysozyme & + & + & - & + & NR & NR & + & + & NR & NR & - \\
\hline $0 \cdot 1 \%$ Lysozyme & + & NR & NR & NR & NR & NR & NR & NR & NR & NR & NR \\
\hline Catalase & - & + & + & + & + & + & + & + & + & + & + \\
\hline Oxidase & - & NR & - & - & - & NR & - & + & - & + & + \\
\hline ONPG & + & + & + & + & - & - & - & NR & NR & NR & NR \\
\hline Arginine dihydrolase & - & - & - & - & - & - & NR & + & NR & NR & NR \\
\hline Ornithine decarboxylase & - & - & - & - & - & - & NR & + & NR & NR & NR \\
\hline Citrate utilization & - & - & - & - & - & $\mathrm{V}$ & - & - & NR & - & + \\
\hline Urease & - & + & - & - & + & + & NR & - & - & + & - \\
\hline Indole production & - & + & - & - & - & - & NR & - & NR & + & + \\
\hline Voges-Proskauer & + & - & - & + & - & + & + & - & NR & NR & NR \\
\hline Gelatin hydrolysis & - & + & - & + & - & - & + & NR & - & NR & NR \\
\hline Nitrate reduction & - & - & $\mathrm{V}$ & $\mathrm{V}$ & $\mathrm{v}$ & $\mathrm{V}$ & + & + & NR & - & + \\
\hline Aesculin hydrolysis & + & + & + & + & + & - & + & + & - & NR & NR \\
\hline \multicolumn{12}{|l|}{ Acid production from: } \\
\hline Glycerol & - & + & + & + & + & - & + & NR & NR & NR & NR \\
\hline D-Arabinose & - & - & + & - & - & - & - & NR & NR & NR & NR \\
\hline L-Arabinose & + & - & + & + & - & - & + & + & NR & - & $\mathrm{V}$ \\
\hline Ribose & + & + & + & + & + & - & + & - & NR & NR & NR \\
\hline D-Xylose & + & - & + & + & + & - & + & - & NR & - & - \\
\hline Adonitol & - & + & - & - & - & - & - & - & NR & NR & NR \\
\hline Methyl $\beta$-xyloside & + & - & + & + & - & - & - & NR & NR & NR & NR \\
\hline Galactose & + & - & + & + & + & + & + & + & NR & NR & NR \\
\hline D-Glucose & + & - & + & + & + & + & + & + & NR & + & + \\
\hline D-Fructose & + & - & + & + & + & $\mathrm{V}$ & + & NR & NR & NR & NR \\
\hline D-Mannose & + & - & + & + & + & + & + & NR & NR & NR & NR \\
\hline L-Sorbose & - & - & - & - & - & $\mathrm{V}$ & - & NR & NR & NR & NR \\
\hline Rhamnose & - & - & + & - & - & - & - & + & NR & NR & NR \\
\hline Inositol & - & - & + & - & + & - & - & + & NR & NR & NR \\
\hline Mannitol & - & - & + & + & + & + & + & + & NR & - & $\mathrm{V}$ \\
\hline Sorbitol & - & - & - & - & - & - & - & + & NR & NR & NR \\
\hline Methyl $\alpha$-D-mannoside & - & - & - & - & - & - & $\mathrm{V}$ & NR & NR & NR & NR \\
\hline
\end{tabular}


Table 2 (cont.)

\begin{tabular}{|c|c|c|c|c|c|c|c|c|c|c|c|}
\hline Characteristic & 1 & 2 & 3 & 4 & 5 & 6 & 7 & 8 & 9 & 10 & 11 \\
\hline Methyl $\alpha$-D-glucoside & - & - & + & + & + & $\mathrm{V}$ & $\mathrm{V}$ & NR & NR & NR & NR \\
\hline$N$-Acetylglucosamine & + & + & + & - & - & - & - & + & NR & NR & NR \\
\hline Amygdalin & + & - & + & + & - & - & + & - & NR & NR & NR \\
\hline Arbutin & + & + & + & + & - & - & + & NR & NR & NR & NR \\
\hline Salicin & + & - & + & + & - & - & + & - & NR & NR & NR \\
\hline Cellobiose & + & - & + & + & - & - & + & NR & NR & NR & NR \\
\hline Lactose & + & - & + & + & - & - & + & + & NR & NR & NR \\
\hline Melibiose & + & + & + & + & + & $\mathrm{V}$ & + & NR & NR & NR & NR \\
\hline Trehalose & - & + & + & + & + & + & + & + & NR & NR & NR \\
\hline Inulin & - & - & + & + & - & - & $\mathrm{V}$ & - & NR & NR & NR \\
\hline Melezitose & - & - & + & + & - & - & - & NR & NR & NR & NR \\
\hline D-Raffinose & + & + & + & + & + & - & + & + & NR & NR & NR \\
\hline Starch & + & + & + & + & + & - & + & NR & NR & + & + \\
\hline Glycogen & + & - & + & + & + & - & + & NR & NR & NR & NR \\
\hline Xylitol & - & - & - & - & - & $\mathrm{V}$ & - & NR & NR & NR & NR \\
\hline$\beta$-Gentiobiose & + & + & + & + & - & - & $\mathrm{V}$ & NR & NR & NR & NR \\
\hline D-Turanose & - & - & + & + & + & $\mathrm{V}$ & + & NR & NR & NR & NR \\
\hline L-Fucose & - & - & + & - & - & - & NR & NR & NR & NR & NR \\
\hline Gluconate & - & - & + & - & - & - & - & NR & NR & NR & NR \\
\hline
\end{tabular}
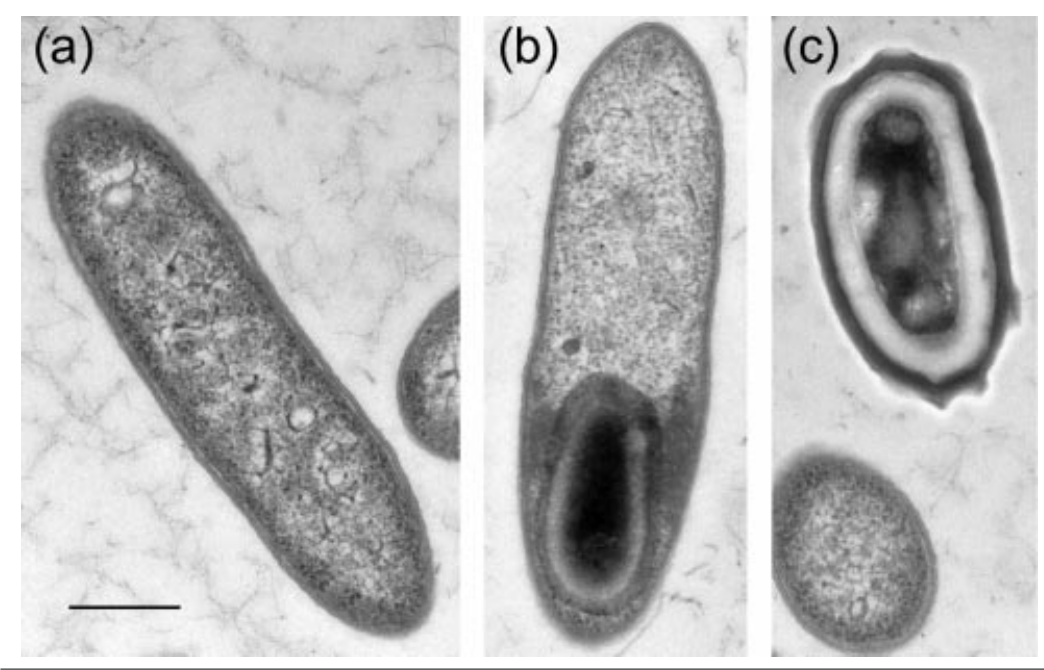

Fig. 1. Transmission electron micrographs of a vegetative cell (a), an endospore in a swollen sporangium (b) and an endospore (c) of isolate MOL722 ${ }^{\top}$ from a 3 day culture on sheep-blood agar. Bar, $0.4 \mu \mathrm{m}$. to five fragments were detected in the restriction patterns (Fig. 3b, c). However, they hybridized only to equally sized fragments. From these experiments, it is not evident how many $16 \mathrm{~S}$ rRNA genes of type A or B are present in the novel strain. A more precise investigation of the rRNA operons would require much more detailed analysis. Nevertheless, from the Southern blot analysis, it is concluded that strain MOL $722^{\mathrm{T}}$ contains at least six to eight different rRNA operons, which is in good agreement with cloning experiments, where seven different sequences were found.

rRNA sequences are, in general, believed to show low variability within species (Woese, 1987). However, Clayton et al. (1995) reported unexpected high levels of intraspecific variation (within and between strains) of prokaryotic 16S rRNA sequences deposited in GenBank. Twenty-six per cent of sequence pairs (two deposited sequences from one species) exhibited differences of more than $1 \%$. In bacteria, rRNA operons are present in numbers of one to 15 (Klappenbach et al., 2001). Few studies address the question of heterogeneity among multiple 16S rRNA operons; the reported differences range from 0 to $5 \%$ (Bricker, 2000; Cilia et al., 1996; Liefting et al., 1996; Mylvaganam \& Dennis, 1992; Ninet et al., 1996; Nubel et al., 1996; Pettersson et al., 1998). In Paenibacillus polymyxa, for example, a maximum of eight variant positions were found in a fragment of $347 \mathrm{bp}$ by pairwise comparison of the six sequences, equivalent to a $2.3 \%$ sequence difference (Nubel et al., 
Table 3. Cellular fatty acid composition of strain MOL722 ${ }^{\top}$ and several other species of the genus Paenibacillus

Values are percentages of total fatty acids. Data for reference species were taken from Daane et al. (2002), Shida et al. (1997a) and Tcherpakov et al. (1999). ND, Not detected.

\begin{tabular}{|lcc|}
\hline Fatty acid & MOL722 $^{\mathrm{T}}$ & Paenibacillus spp. \\
\hline $\mathrm{C}_{14: 0}$ & $8 \cdot 9$ & $0 \cdot 2-3 \cdot 7$ \\
$\mathrm{C}_{15: 0}$ & $\mathrm{ND}$ & $\mathrm{ND}-3 \cdot 5$ \\
$\mathrm{C}_{16: 0}$ & $25 \cdot 4$ & $1 \cdot 5-24 \cdot 7$ \\
iso $_{14: 0}$ & $8 \cdot 5$ & $\mathrm{ND}-7 \cdot 9$ \\
iso $\mathrm{C}_{15: 0}$ & $5 \cdot 8$ & $0 \cdot 2-14 \cdot 4$ \\
iso $\mathrm{C}_{16: 0}$ & $4 \cdot 1$ & $1 \cdot 3-27 \cdot 1$ \\
iso $\mathrm{C}_{17: 0}$ & $\mathrm{ND}$ & $0 \cdot 2-7 \cdot 1$ \\
anteiso $\mathrm{C}_{15: 0}$ & $41 \cdot 4$ & $34 \cdot 5-81 \cdot 0$ \\
anteiso $\mathrm{C}_{17: 0}$ & $\mathrm{ND}$ & $1 \cdot 0-30 \cdot 2$ \\
$\mathrm{C}_{16: 1} \omega 11$ & $\mathrm{ND}$ & $\mathrm{ND}-5 \cdot 2$ \\
iso $\mathrm{C}_{17: 1} \omega 10$ & $\mathrm{ND}$ & $\mathrm{ND}-1 \cdot 7$ \\
\hline
\end{tabular}

1996) and, in the archaeon Haloarcula marismortui, even a 5\% difference has been reported (Mylvaganam $\&$ Dennis, 1992). These findings document that heterogeneities between 16S rRNA genes seems to be a common phenomenon and, that for species identification, 16S rDNA analysis has to be interpreted with care.

\section{Phylogenetic analysis}

Comparative database analysis using the fastA algorithm (Pearson \& Lipman, 1988) with the six cloned full-length $16 \mathrm{~S}$ rRNA genes suggested that strain MOL722 ${ }^{\mathrm{T}}$ belongs to the genus Paenibacillus. Additionally, the signature sequences BG3 (Ash et al., 1993) and PAEN515F (Shida et al., 1997a) for the genus Paenibacillus were also found within the $16 \mathrm{~S}$ rDNA sequences of our strain. Levels of $16 \mathrm{~S}$ rDNA sequence similarity were $98.5 \%$ to Paenibacillus sp. (a)

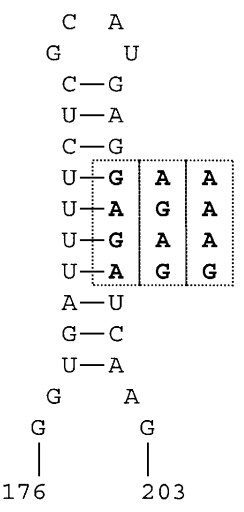

(b)

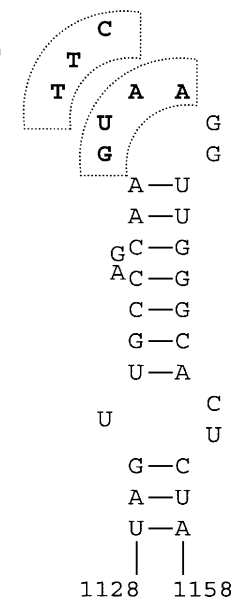

Fig. 2. Proposed secondary structures of the two variable regions of strain MOL722 $16 \mathrm{~S}$ rRNA. The variable positions are framed. (a) Helix 10 in the V2 region (Neefs et al., 1993), with the three different sequences possible at positions 195-198. (b) Helix 43 in the V7 region, with the two observed terminal loops at positions 1141-1144. Numbers correspond to positions in the sequence of clone type $A$.

isolate P15-9 and between 93.7\% (Paenibacillus illinoisensis and $P$. polymyxa) and $87.2 \%$ (Paenibacillus alvei) to other paenibacilli. However, the strain also showed relatively high similarities to other bacilli, e.g. $93.7 \%$ to Bacillus chitinolyticus, $93 \%$ to Bacillus ehimensis and $91.5 \%$ to Bacillus vortex. Database searches with these Bacillus species suggest that the next relatives of $B$. chitinolyticus, B. ehimensis and $B$. vortex are members of the genus Paenibacillus. This indicates that these three species may be misclassified as Bacillus species and are probably indeed members of Paenibacillus. After multiple sequence alignment, the similarities were $99 \cdot 2 \%$ to Paenibacillus sp. isolate P15-9 and between 93.5\% (P. illinoisensis) and $89.1 \%$ (Paenibacillus alginolyticus) to the other paenibacilli. This is, to the knowledge of the authors, the first time that intragenus identities have been found to be below the value reported by Shida et al. (1997b)

Table 4. Variable $16 \mathrm{~S}$ rDNA positions between $\mathrm{MOL}_{22}{ }^{\top}$ clones

Numbers correspond to positions in the sequence of clone type A. ND, Not determined.

\begin{tabular}{|lccccccccc|}
\hline Clone type & $\mathbf{7 3}$ & $\mathbf{8 9}$ & $\mathbf{1 9 5}-\mathbf{1 9 8}$ & $\mathbf{2 0 9}$ & $\mathbf{2 2 3}$ & $\mathbf{1 0 1 2}$ & $\mathbf{1 1 4 1 - 1 1 4 4}$ & $\mathbf{1 2 7 0}$ & $\mathbf{1 5 3 5}$ \\
\hline A1 & A & A & AAAG & C & A & G & GTAA & A & C \\
A2 & A & A & AGAG & C & G & G & GTAA & G & C \\
A3a & A & A & GAGA & C & A & G & GTAA & A & T \\
A3b* & ND & ND & GAGA & T & A & G & GTAA & A & C \\
B1 & A & G & AAAG & C & A & A & TTC- & G & C \\
B2 & G & G & AGAG & C & A & G & TTC- & G & C \\
B3 & A & G & GAGA & T & A & A & TTC- & G & T \\
\hline
\end{tabular}

* This clone contained only a partial sequence as insert. 


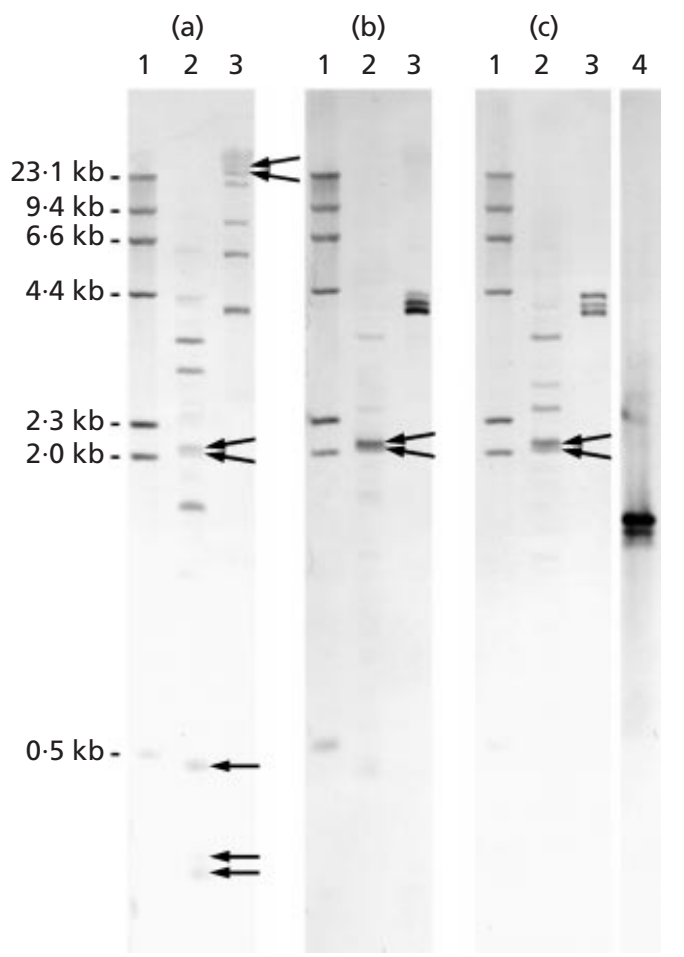

Fig. 3. Southern blot. Chromosomal DNA from strain MOL722 was digested with HindIII (lanes 2) and Kpnl (lanes 3). Lanes 1 contain markers, lane 4 in (c) is a PCR product of the 16S rDNA of strain MOL722 ${ }^{\top}$. Fragments were separated by agarose gel electrophoresis and blots were hybridized with probe DIG-Bact8s (a), DIG-MOL722-TTC (b) or DIG-MOL722-GTAA (c). Arrows indicate double bands and bands smaller than $0.5 \mathrm{~kb}$, which are of low intensity. Bands of low intensity but larger than $2.0 \mathrm{~kb}$ were interpreted as partially digested fragments.

$(89.9 \%)$ for members of the genus Paenibacillus. Although DNA-DNA reassociation is still considered the ' gold standard' in the present species definition, no DNA-DNA reassociation experiments were performed in this study because the similarity values to other species were low. According to Stackebrandt \& Goebel (1994), DNA pairing studies need to be performed at rDNA similarities of $\geqslant 97 \%$. Below this value, it can be assumed that the strains belong to two different species or even higher taxonomic groups. Keswani \& Whitman (2001) even suggested a threshold value of $98.6 \%$ similarity for taxa where the rRNA sequences do not possess non-ultrametric properties and Drancourt et al. (2000) used 99\% for species identification.

The phylogenetic affiliation was inferred using different programs, neighbour-joining, UPGMA, Fitch-Margoliash and maximum-parsimony, of the PHYLIP package (Felsenstein, 1989) and maximumparsimony of the ARB package (Strunk et al., 1999). All methods placed the six sequences of strain MOL $722^{\mathrm{T}}$ side by side and together with the sequence of Paenibacillus sp. isolate P15-9 as a monophyletic, deeply branching clade within the genus Paenibacillus.

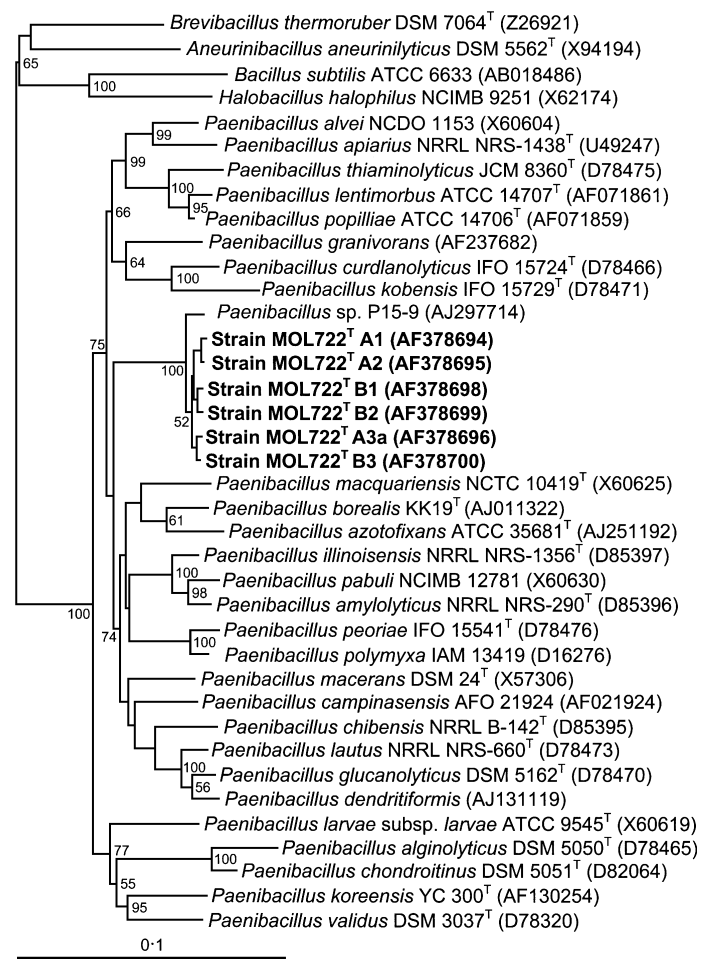

Fig. 4. Phylogenetic relationship of strain $M O L 722^{\top}$ to most validly published Paenibacillus species and some other aerobic, rod-shaped, endospore-forming bacteria based on 16S rRNA gene sequences. The branching pattern was generated by the neighbour-joining method (with Jukes-Cantor distance correction). A total of 1430 aligned bases between positions 41 and 1423 (E. coli numbering; Brosius et al., 1978) were used for this analysis. Numbers indicate bootstrap values greater than 50 (of 100 cycles). Sequence accession numbers are in parentheses. Bar, $0 \cdot 1$ nucleotide substitutions per site.

The phylogram in Fig. 4 shows the detailed evolutionary relationship of strain MOL $722^{\mathrm{T}}$ and most validly described paenibacilli as deduced by the neighbour-joining method.

Based on all of the above results, it is concluded that strain MOL722 ${ }^{\mathrm{T}}$ represents a novel species of Paenibacillus, for which the name Paenibacillus turicensis sp. nov. is proposed. It is assumed that this novel isolate was probably a contaminant in the specimen and does not have clinical significance.

\section{Description of Paenibacillus turicensis sp. nov.}

Paenibacillus turicensis (tu.ri.cen'sis. L. adj. turicensis of Turicum, the Latin name of Zürich, where the type strain was isolated).

Cells are Gram-positive, motile rods, $1 \cdot 5-3 \times 0 \cdot 5-1 \mu \mathrm{m}$ in size. Terminal to subterminal oval spores are formed in swollen sporangia. On sheep-blood agar, the nonhaemolytic colonies were greyish-white with a convex elevation. Facultatively anaerobic, growing at 15$48{ }^{\circ} \mathrm{C}$ and $\mathrm{pH} 5 \cdot 5-9 \cdot 5$ with optima of $37-42{ }^{\circ} \mathrm{C}$ and 
$\mathrm{pH}$ 7. Doubling time under optimal conditions is $45 \mathrm{~min}$. Grows in the presence of up to $5 \% \mathrm{NaCl}$ and $0 \cdot 1 \%$ lysozyme. Negative for catalase, oxidase, urease, nitrate reduction and indole production. Positive for $\beta$ galactosidase and Voges-Proskauer reaction. Starch is hydrolysed. Ferments L-arabinose, ribose, D-xylose, methyl $\beta$-xyloside, galactose, D-glucose, D-fructose, $\mathrm{D}-$ mannose, $N$-acetylglucosamine, amygdalin, arbutin, aesculin, salicin, cellobiose, maltose, lactose, melibiose, sucrose, D-raffinose, glycogen, $\beta$-gentiobiose and 5 -ketogluconate (weak). The major fatty acids are anteiso- $\mathrm{C}_{15: 0}(41 \%), \mathrm{C}_{16: 0}(25 \%), \mathrm{C}_{14: 0}(9 \%)$ and iso$\mathrm{C}_{14: 0}(9 \%)$. The bacterium contains at least six to eight $16 \mathrm{~S}$ rRNA genes. The 16S rDNA shares $98.5 \%$ sequence similarity with Paenibacillus sp. isolate P15-9 and $93 \cdot 7-87 \cdot 2 \%$ similarity with other paenibacilli. The type strain is strain MOL722 $2^{\mathrm{T}}\left(=\mathrm{DSM} 14349^{\mathrm{T}}=\right.$ NCCB $100011^{\mathrm{T}}$ ), which harbours up to $0 \cdot 77 \%$ heterogeneity between $16 \mathrm{~S}$ rRNA genes, including, among others, an insertion of one nucleotide.

\section{ACKNOWLEDGEMENTS}

We thank Dr F. Pranada for isolation of the strain and for clinical information, Jacqueline Lüthy and P. Landis for technical assistance, Dr T. Bächi and Therese Bruggmann for the electron micrograph and Dr A. von Graevenitz for helpful discussion and careful reading of the manuscript.

\section{REFERENCES}

Aguilera, M., Monteoliva-Sánchez, M., Suárez, A., Guerra, V., Lizama, C., Bennasar, A. \& Ramos-Cormenzana, A. (2001). Paenibacillus jamilae sp. nov., an exopolysaccharide-producing bacterium able to grow in olive-mill wastewater. Int J Syst Evol Microbiol 51, 1687-1692.

Ash, C., Priest, F. G. \& Collins, M. D. (1993). Molecular identification of rRNA group 3 bacilli (Ash, Farrow, Wallbanks and Collins) using a PCR probe test. Proposal for the creation of a new genus Paenibacillus. Antonie van Leeuwenhoek 64, 253-260.

Berghammer, H. \& Auer, B. (1993). 'Easypreps': fast and easy plasmid minipreparation for analysis of recombinant clones in E. coli. Biotechniques 14, 524-528.

Bosshard, P. P., Stettler, R. \& Bachofen, R. (2000). Seasonal and spatial community dynamics in the meromictic Lake Cadagno. Arch Microbiol 174, 168-174.

Bosshard, P. P., Zbinden, R. \& Altwegg, M. (2002). Turicibacter sanguinis gen. nov., sp. nov., a novel anaerobic, Gram-positive bacterium. Int J Syst Evol Microbiol 52, 1263-1266.

Bricker, B. J. (2000). Characterization of the three ribosomal RNA operons $r r n A, r r n B$, and $r r n C$, from Brucella melitensis. Gene 255, $117-126$.

Brosius, J., Palmer, M. L., Kennedy, P. J. \& Noller, H. F. (1978). Complete nucleotide sequence of a $16 \mathrm{~S}$ ribosomal RNA gene from Escherichia coli. Proc Natl Acad Sci U S A 75, 4801-4805.

Chung, Y. R., Kim, C. H., Hwang, I. \& Chun, J. (2000). Paenibacillus koreensis sp. nov., a new species that produces an iturin-like antifungal compound. Int J Syst Evol Microbiol 50, 1495-1500.

Cilia, V., Lafay, B. \& Christen, R. (1996). Sequence heterogeneities among $16 \mathrm{~S}$ ribosomal RNA sequences, and their effect on phylogenetic analyses at the species level. Mol Biol Evol 13, 451-461.

Clayton, R. A., Sutton, G., Hinkle, P. S., Jr, Bult, C. \& Fields, C. (1995). Intraspecific variation in small-subunit rRNA sequences in GenBank: why single sequences may not adequately represent prokaryotic taxa. Int J Syst Bacteriol 45, 595-599.

Daane, L. L., Harjono, I., Barns, S. M., Launen, L. A., Palleroni, N. J.
\& Häggblom, M. M. (2002). PAH-degradation by Paenibacillus spp. and description of Paenibacillus naphthalenovorans sp. nov., a naphthalene-degrading bacterium from the rhizosphere of salt marsh plants. Int J Syst Evol Microbiol 52, 131-139.

Devereux, J., Haeberli, P. \& Smithies, O. (1984). A comprehensive set of sequence analysis programs for the VAX. Nucleic Acids Res 12, 387-395.

Drancourt, M., Bollet, C., Carlioz, A., Martelin, R., Gayral, J. P. \& Raoult, D. (2000). 16S ribosomal DNA sequence analysis of a large collection of environmental and clinical unidentifiable bacterial isolates. $J$ Clin Microbiol 38, 3623-3630.

Felsenstein, J. (1989). PHYLIP - phylogeny inference package (version 3.2). Cladistics 5, 164-166.

Fischer-Romero, C., Lüthy-Hottenstein, J. \& Altwegg, M. (2000). Development and evaluation of a broad-range PCR-ELISA assay with Borrelia burgdorferi and Streptococcus pneumoniae as model organisms for reactive arthritis and bacterial meningitis. J Microbiol Methods 40, $79-88$.

Fox, G. E., Stackebrandt, E., Hespell, R. B. \& 16 other authors (1980). The phylogeny of prokaryotes. Science 209, 457-463.

Gutell, R. R., Larsen, N. \& Woese, C. R. (1994). Lessons from an evolving rRNA: $16 \mathrm{~S}$ and $23 \mathrm{~S}$ rRNA structures from a comparative perspective. Microbiol Rev 58, 10-26.

Keswani, J. \& Whitman, W. B. (2001). Relationship of 16S rRNA sequence similarity to DNA hybridization in prokaryotes. Int $J$ Syst Evol Microbiol 51, 667-678.

Klappenbach, J. A., Saxman, P. R., Cole, J. R. \& Schmidt, T. M. (2001). rrndb: the Ribosomal RNA Operon Copy Number Database. Nucleic Acids Res 29, 181-184.

Lane, D. J. (1991). 16S/23S rRNA sequencing. In Nucleic Acid Techniques in Bacterial Systematics, pp. 115-175. Edited by E. Stackebrandt \& M. Goodfellow. Chichester: Wiley.

Liefting, L. W., Andersen, M. T., Beever, R. E., Gardner, R. C. \& Forster, R. L. (1996). Sequence heterogeneity in the two 16S rRNA genes of Phormium yellow leaf phytoplasma. Appl Environ Microbiol 62, 3133-3139.

Martínez-Murcia, A. J., Antón, A. I. \& Rodríguez-Valera, F. (1999). Patterns of sequence variation in two regions of the 16S rRNA multigene family of Escherichia coli. Int J Syst Bacteriol 49, 601-610.

Mylvaganam, S. \& Dennis, P. P. (1992). Sequence heterogeneity between the two genes encoding 16S rRNA from the halophilic archaebacterium Haloarcula marismortui. Genetics 130, 399-410.

Neefs, J. M., Van de Peer, Y., De Rijk, P., Chapelle, S. \& De Wachter, R. (1993). Compilation of small ribosomal subunit RNA structures. Nucleic Acids Res 21, 3025-3049.

Ninet, B., Monod, M., Emler, S., Pawlowski, J., Metral, C., Rohner, P., Auckenthaler, R. \& Hirschel, B. (1996). Two different 16S rRNA genes in a mycobacterial strain. J Clin Microbiol 34, 2531-2536.

Nubel, U., Engelen, B., Felske, A., Snaidr, J., Wieshuber, A., Amann, R. I., Ludwig, W. \& Backhaus, H. (1996). Sequence heterogeneities of genes encoding 16S rRNAs in Paenibacillus polymyxa detected by temperature gradient gel electrophoresis. J Bacteriol 178, 5636-5643.

Pearson, W. R. \& Lipman, D. J. (1988). Improved tools for biological sequence comparison. Proc Natl Acad Sci U S A 85, 2444-2448.

Pettersson, B., Bolske, G., Thiaucourt, F., Uhlen, M. \& Johansson, K. E. (1998). Molecular evolution of Mycoplasma capricolum subsp. capripneumoniae strains, based on polymorphisms in the 16S rRNA genes. J Bacteriol 180, 2350-2358.

Reischl, U., Feldmann, K., Naumann, L., Gaugler, B. J., Ninet, B., Hirschel, B. \& Emler, S. (1998). 16S rRNA sequence diversity in Mycobacterium celatum strains caused by presence of two different copies of 16S rRNA gene. J Clin Microbiol 36, 1761-1764.

Shida, O., Takagi, H., Kadowaki, K., Nakamura, L. K. \& Komagata, K. (1997a). Transfer of Bacillus alginolyticus, Bacillus chondroitinus, Bacillus curdlanolyticus, Bacillus glucanolyticus, Bacillus kobensis, and Bacillus thiaminolyticus to the genus Paenibacillus and emended description of the genus Paenibacillus. Int J Syst Bacteriol 47, 289-298. 
Shida, O., Takagi, H., Kadowaki, K., Nakamura, L. K. \& Komagata, K. (1997b). Emended description of Paenibacillus amylolyticus and description of Paenibacillus illinoisensis sp. nov. and Paenibacillus chibensis sp. nov. Int J Syst Bacteriol 47, 299-306.

Stackebrandt, E. \& Goebel, B. M. (1994). Taxonomic note: a place for DNA-DNA reassociation and 16S rRNA sequence analysis in the present species definition in bacteriology. Int J Syst Bacteriol 44, 846-849.

Stackebrandt, E., Rainey, F. A. \& Ward-Rainey, N. L. (1997).

Proposal for a new hierarchic classification system, Actinobacteria classis nov. Int $J$ Syst Bacteriol 47, 479-491.

Strunk, O., Gross, O., Reichel, B. \& 11 other authors (1999). ARB: a software environment for sequence data. Department of Microbiology, Technische Universität München, Munich, Germany. http://www.biol.chemie.tu-muenchen.de

Tcherpakov, M., Ben-Jacob, E. \& Gutnick, D. L. (1999). Paenibacillus dendritiformis sp. nov., proposal for a new pattern-forming species and its localization within a phylogenetic cluster. Int J Syst Bacteriol 49, 239-246.

von Graevenitz, A. \& Funke, G. (1996). An identification scheme for rapidly and aerobically growing gram-positive rods. Zentbl Bakteriol 284, 246-254.

von Graevenitz, A., Pünter, V., Gruner, E., Pfyffer, G. E. \& Funke, G. (1994). Identification of coryneform and other gram-positive rods with several methods. APMIS 102, 381-389.

Woese, C. R. (1987). Bacterial evolution. Microbiol Rev 51, 221-271.

Woese, C. R., Kandler, O. \& Wheelis, M. L. (1990). Towards a natural system of organisms: proposal for the domains Archaea, Bacteria, and Eucarya. Proc Natl Acad Sci U S A 87, 4576-4579.

Yoon, J.-H., Yim, D. K., Lee, J.-S., Shin, K.-S., Sato, H. H., Lee, S. T., Park, Y. K. \& Park, Y.-H. (1998). Paenibacillus campinasensis sp. nov., a cyclodextrin-producing bacterium isolated in Brazil. Int $J$ Syst Bacteriol 48, 833-837. 